\title{
O Teatro de Mamulengos de ontem e de hoje: a importância do reconhecimento do Teatro de Bonecos Tradicional Brasileiro como patrimônio imaterial cultural do Brasil
}

The Mamulengo Puppet Theatre of yesterday and today: the importance of recognizing the Traditional Brazilian Puppet Theatre as intangible cultural heritage of Brazil

\author{
Kely Elias de Castro ${ }^{1}$ \\ kelydecastro@gmail.com
}

\section{Resumo}

Este artigo propõe uma reflexão sobre o Teatro de Mamulengos na atualidade à luz de sua história, acentuando sua resistência como manifestação cultural ao longo dos tempos. Procura analisar elementos da atualidade que influem na sobrevivência e renovação desta linguagem artística, bem como características que endossam sua importância dentro da ideia de identidade nacional. Discorre sobre aspectos relacionados ao recente reconhecimento deste teatro como patrimônio imaterial e cultural do Brasil, pelo Iphan (Instituto do Patrimônio Histórico e Artístico Nacional). Para tanto, utiliza bibliografia sobre o teatro de Mamulengos e patrimônio imaterial.

Palavras-Chave: Teatro de bonecos; Teatro de Mamulengos; Patrimônio cultural.

\begin{abstract}
This article proposes a reflection about the Mamulengo Puppet Theatre today in light of its history, emphasinzing its resistence as cultural manifestation over time. We analyze the current elements that influence the survival and renewal of this artistic language, as well as other characteristics that endorse its importance to the idea of national identity. It discusses some issues related to the recent recognition of this theatre genre as intangible cultural heritage of Brazil by Iphan (Nacional Institute of Historic and Artistic Patrimony). This debate is based on literature about Mamulengo Puppet Theatre and intangible cultural heritage.
\end{abstract}

Keywords: Puppet theatre; Mamulengo puppet theatre; Cultural heritage.

1 Doutoranda em Artes, no Instituto de Artes da Universidade Estadual Paulista (Unesp), e mestre em Artes pela Escola de Comunicação e Artes da Universidade de São Paulo (ECA/USP). 


\section{Introdução}

No ano de 2015, em que o teatro de bonecos tradicional nordestino recebe o título de Patrimônio Imaterial Cultural do Brasil pelo Iphan, este artigo busca realizar uma breve reflexão sobre a importância deste teatro e sua presença na atualidade.

Principiamos por considerar que o Registro de Bens Culturais de Natureza Imaterial e o Programa Nacional do Patrimônio Imaterial têm apenas quinze anos de existência em nosso país, sendo que os estudos para o registro do teatro de bonecos tradicional do Brasil, como patrimônio imaterial, começaram há oito anos. Entretanto, apesar de apenas agora ter sido oficializada, a trajetória da investigação sobre o fazer dos mestres e outros envolvidos no teatro de bonecos acompanhou grande parte do período da construção da ideia de patrimônio imaterial no Brasil.

Do ano 2000 para cá, vimos algumas manifestações artísticas populares se tornarem oficialmente nosso patrimônio, por exemplo: Jongo do Sudeste (2005), Matrizes do Samba do Rio de Janeiro (2007), Tambor de Crioula do Maranhão (2007), Samba de Roda do Recôncavo Baiano (2008), Frevo do Carnaval de Recife (2012) e a Roda de Capoeira (2014). São práticas realizadas por uma determinada comunidade que formam seus jeitos de fazer, de pensar, de se comportar, ou seja, estabelecem uma identidade popular ou, nestes casos, artística. Em relação ao teatro de bonecos nordestino, o dossiê para o registro deste patrimônio argumenta:

O Registro do Teatro de Bonecos Popular do Nordeste - Mamulengo, Babau, João Redondo e Cassimiro - como Patrimônio Cultural do Brasil e sua inscrição no livro Formas de Expressão, justifica-se considerando a originalidade e a tradição dessa expressão cênica, 175 repassadas de mestre para discípulo, de pai para filho, de geração para geração. Uma tradição que revela uma das facetas da cultura brasileira, onde brincantes, através da arte dos bonecos, encenam histórias apreendidas na tradição que falam de relações sociais estabelecidas em um dado período da sociedade nordestina e de histórias que continuam revelando seu cotidiano, através dos novos enredos, personagens, música, linguagem verbal, das cores e da alegria que são inerentes ao seu contexto social. (BRASIL, 2014, p. 174).

O teatro de bonecos tradicional é uma manifestação cultural popular presente em diferentes países e que recebe influências culturais que determinam suas características. Para citar alguns, há o Guignol, na França; Punch, na Inglaterra; Karagós, na Turquia; Fantoccini, na Itália e Vidouchaka, na Índia. Nas Américas, o dossiê citado enfatiza que o Brasil é o único país que possui um patrimônio desta natureza. Muito embora a tradição deste tipo de teatro esteja presente em grande parte do país, foi na região nordeste que mais se desenvolveu, cresceu e resistiu até os dias de hoje.

Mesmo falando apenas da região nordeste, a variação do teatro de bonecos tradicional é relativamente grande e recebeu diferentes nomes: Mamulengo (Pernambuco), Babau (Paraíba), João Redondo (Rio Grande do Norte) e Cassimiro Coco (Maranhão, Alagoas, Ceará e Piau1). Não por acaso, a denominação Mamulengo se tornou generalizante quando se fala em teatro de bonecos popular brasileiro, por isso aqui vamos utilizá-la.

Os registros históricos mais antigos sobre a existência do teatro de Mamulengos são do século XIX, porém, não se sabe ao certo como e quando teria sido seu início. Da mesma forma, incertezas também cercam a origem de seu nome, que se cogita, entre outras teses menos aceitas, ter vindo da expressão "mão molenga", uma referência ao ágil movimento da mão na manipulação do boneco de luva no Mamulengo. Ainda, é comum encontrarmos nos estudos sobre o teatro de bonecos popular brasileiro a afirmação de que sua genealogia é portuguesa e católica. Teria raízes nas festividades natalinas, mais especificamente na construção e na animação de presépios. Contudo, têm crescido, ainda que morosamente, as pesquisas que apontam as origens africanas deste teatro.

A tese de que o boneco popular brasileiro teria sua ascendência da terra dos colonizadores do Brasil se confronta com a história, contada por antigos mamulengueiros, de que a brincadeira teria nascido em uma senzala no Brasil. Segundo essa lenda, depois de ser açoitado por um senhor cruel, um negro chamado Tião teria esculpido a face deste torturador num tronco de madeira. Teria então enrolado a escultura em trapos e com ela iniciado uma imitação dos trejeitos de seu senhor, para a diversão dos outros negros na senzala. Denunciado, o escravo foi surpreendido pelo senhor no meio da brincadeira, porém, ao invés de interromper a ação para castigá-lo, seu senhor se pôs a apreciar a história até o fim. Tião foi perdoado, mas a esposa do senhor não se conformou com o fato de 
seu marido ter permitido tamanha zombaria. Então, o senhor teria ido até Tião e mandado que ele fizesse também uma escultura da sinhá, e que mostrasse a brincadeira a ela. O negro ficou assustado, imaginando que desta vez seria morto, mas para sua surpresa nem mesmo sinhá, que seria ainda mais cruel que seu senhor, pôde resistir ao encanto da brincadeira. Desde então, Tião teria sido liberado para continuar fazendo esta diversão em seus momentos de descanso, e, assim, teria se tornado o primeiro mamulengueiro da história do Brasil (FILHO, 1987, p. 73).

O pesquisador e brincante Chico Simões comenta a lenda que, apesar de ficcional, é conhecida por todos os mestres e citada em estudos acadêmicos na área:

Esta história é uma ficção, provavelmente, criada na imaginação fértil de um ou vários mamulengueiros, mas prefiro essa ficção forjada para expressar sentimentos verdadeiros, para revelar relações sociais, culturais, morais, políticas e econômicas de um tempo e de um lugar, para denunciar e combater preconceitos reais, que as histórias documentais, científicas, oficiais, que nem sempre querem revelar (SIMÕES, 2005, p. 180).

Certamente, a hipótese de que o Mamulengo nasceu em uma senzala no Brasil, como um instrumento de resistência, crítica e diversão, identifica-o mais com o povo brasileiro do que a tese de que este seria um desdobramento de formas de bonecos trazidos pelos portugueses. Sabe-se que Anchieta utilizava bonecos em suas tentativas de catequização dos índios, mas também é sabido que muitas etnias indígenas confeccionavam bonecos para diferentes fins, desde representações dos deuses às mais puras brincadeiras infantis.

Desta forma, a verdadeira origem do Mamulengo continua controversa, mas o que se destaca nesse tipo de teatro é a sua resistência ao longo do tempo. Mesmo tendo sofrido modificações necessárias à sua sobrevivência, ele se manteve absolutamente atual em seu propósito: o de falar do povo para o povo.

Antes de iniciarmos este breve voo sobre essa arte popular tradicional, vale destacar uma característica peculiar e não menos importante que tantos outros aspectos específicos do Mamulengo: diz-se dessa arte, brincadeira; de seu objeto, brinquedo; de seu artista, brincante. É possível que elucubrações

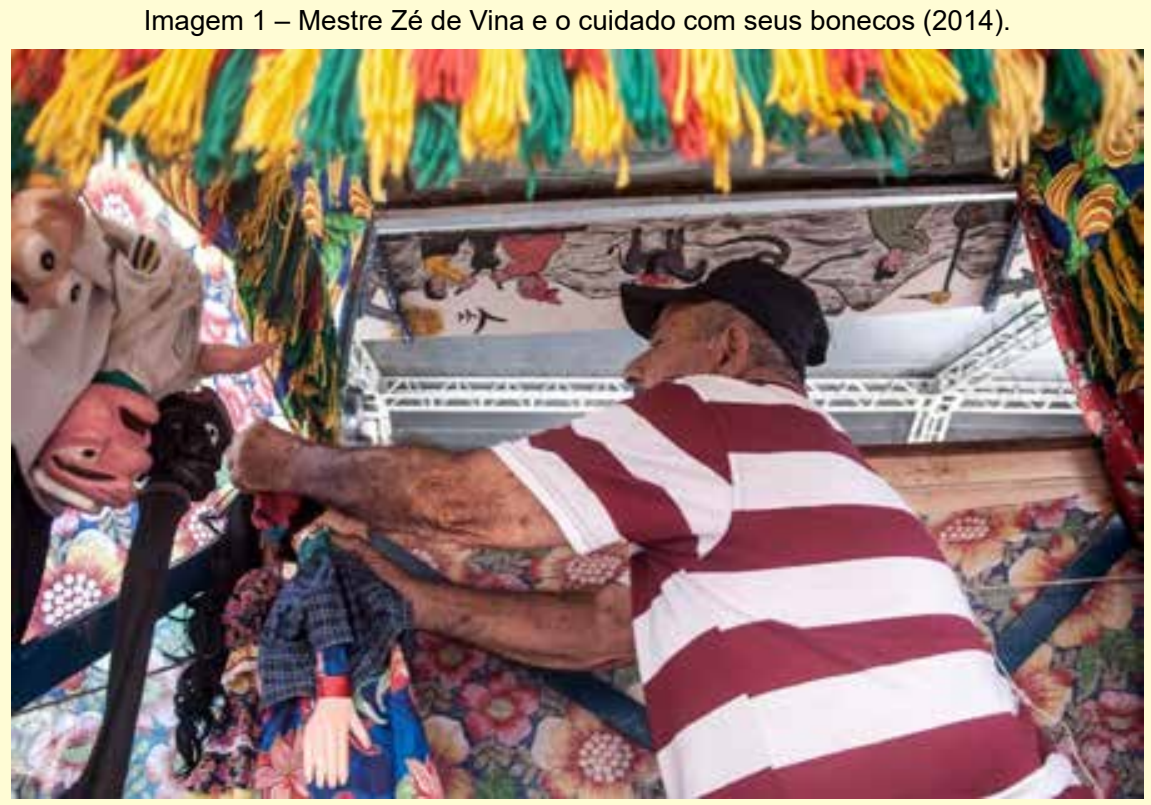

Fonte: Anna Piccolo (acervo pessoal). sobre esta terminologia específica possam reduzir o conteúdo poético e as tantas possibilidades de associação entre os conceitos de arte e brincadeira. Contudo, não podemos nos furtar de destacar ao menos dois aspectos nos quais se baseia esta arte: a liberdade e a inocência.

Inocência, no sentido da inimputabilidade e da singeleza. Como nos ensina a lenda do escravo Tião, o mamulengueiro não pode ser culpado, ou punido, pelas críticas ou zombarias que fazem seus bonecos. A malícia está no brinquedo e não no brincante. São inúmeras as histórias que pesquisadores relatam sobre a nítida separação que os mestres fazem entre eles próprios e seus bonecos. Por exemplo, quando Hermilo Borba Filho conta sobre o mamulengueiro José Petronilo, diz: 
Dossiê

com o auditório e lança mão de obscenidades que fazem as delícias das senhoras e mocinhas. [...] Tem uma maneira toda especial de falar de seus bonecos, quando os está preparando para a função. Um deles, uma boneca chamada Dona Condessa, mereceu este reparo: "Essa velha é muito assanhada e o senhor vai ver como ela fala" (FILHO, 1987, p. 151).

A inocência é a garantia da inculpabilidade do brincante e está diretamente ligada à outra característica fundamental, a liberdade. Como toda brincadeira, o Mamulengo tem regras próprias que especificam sua arte, mas entre elas é vital a liberdade irrestrita para criar e improvisar. O cerceamento desta liberdade, imposto por diferentes vias, como a tentativa de moralização ou cobranças do mercado cultural, também será tratado aqui, ainda que de maneira breve.

\section{A brincadeira de ontem}

Assim como fazia o escravo Tião, os mestres mamulengueiros brincam nos intervalos do trabalho. Afinal, a grande maioria, além de artista, possui atividade profissional. São feirantes, roceiros, cabeleireiros, pedreiros, pequenos comerciantes, lavradores, etc. São trabalhadores do campo ou da cidade, de origem pobre, muitas vezes, analfabetos. Aprenderam a brincar vendo o outro brincar, normalmente alguém da própria família ou da mesma comunidade.

Essa proximidade é algo importante para a preservação do Mamulengo. Isso porque o mamulengueiro é, em geral, um artista múltiplo: confecciona bonecos, cenários e figurinos; monta suas histórias e roteiros (pode-se dizer que é seu próprio dramaturgo); dirige os músicos e outros participantes da função e é, ainda, produtor, pois normalmente é o responsável pelas negociações acerca das apresentações. Por isso, estar próximo e poder acompanhar quem faz tudo isso é provavelmente a única maneira de apreender de forma completa este ofício, mesmo nos dias hoje.

Cada mestre desenvolve seu jeito próprio de brincar, suas personagens e a formação de seu grupo para a função. Os grupos podem ter vários integrantes: o mestre; o contramestre; os ajudantes que auxiliam dentro da barraca, também chamados de Folgaðões; o Mateus (originário do bumba-meu-boi), que faz um papel similar a um mestre de cerimônias; e os músicos, que tradicionalmente formam uma banda composta por sanfona de oito baixos, triângulo, ou ganzá, e caixa, ou zabumba. Em geral, os mestres são pelo menos acompanhados por um músico, mas também há aqueles que brincam sós.

As apresentações podem ocorrer em diferentes locais, públicos ou não: praças, ruas, comércios, sítios, casas, etc. Não possuem, tradicionalmente, hora para acabar, podendo durar até oito horas, virando a noite. Por conseguinte, o público vai se modificando no decorrer do espetáculo, pois uns chegam, outros saem. Esta é uma peculiaridade curiosa do Mamulengo, pois como a participação do público é de fundamental importância, o mestre deve ser capaz de improvisar com diferentes públicos em uma única função. A plateia se modifica completamente caso a brincadeira adentre a noite, já que, dado certo horário, mulheres e crianças vão embora e predomina o público masculino, frequentemente aquecido pelo consumo de álcool. Então, a brincadeira fica mais livre, sem preocupações morais, e é quando aparecem as piadas mais maliciosas, de sentido sexual (SANTOS, 2007, p. 22).

Os espetáculos não possuem uma estrutura dramática linear, possuem um roteiro (não escrito) acrescido de improvisos e dependem diretamente da participação do público. São formados por passagens, pequenas cenas normalmente criadas a partir da personagem/boneco que podem ser tradicionais ou inventadas pelo brincante. Quando existe uma história, ela nada mais é do que um pretexto para a apresentação dessas passagens, que não necessariamente possuem alguma ligação entre si. Essa estrutura, assim como outros aspectos, como personagens e temas, muito se assemelha à da commedia dell'arte, de origem italiana, o que reforça a ideia de uma suposta raiz europeia para o Mamulengo.

Como já dito, o teatro de Mamulengo é feito pelo povo e para o povo, portanto seus assuntos são 
sempre relativos à classe trabalhadora, seja da cidade ou do campo, ao seu cotidiano, às suas mazelas, às suas crenças e festas. Seu objetivo maior é a diversão, o fazer rir. Para atingir este intento vale tudo: obscenidades, palavrões, escatologias, pancadarias e, inclusive, brincadeiras de cunho pessoal, dirigidas a alguém da plateia.

Este gênero de espetáculo se caracteriza pela hibridez, sendo absolutamente necessária a presença da música, da dança e da poesia. Elas permitem criar um universo particular em que os heróis e vencedores são figuras do povo e o opressor é quem sofre e paga pelo mal. Conforme Fernando Augusto Gonçalves Santos:

\begin{abstract}
Freqüentemente, o Mamulengo é de uma contundência admirável, motivado por uma inspiração fascinante que lhe permite alterar o equilíbrio do mundo, as relações de poder, insurgindo-se contra o maniqueísmo da vida, criando um outro mundo que ele próprio governa, uma situação poético-dramática que incorpora o público. Arranca personagens e temas de um mundo ao qual é sujeito, submisso e pelo qual é explorado, transpondo-os, em transfiguração muito própria, para um mundo onde sua voz, anseios e vontades são ouvidos. Isso tudo na intenção maior de provocar o riso, que gerando a folgança, o alívio, o divertimento, atua como elemento catártico e de grande comunicabilidade (SANTOS, 2007, p. 20).
\end{abstract}

Os bonecos são tradicionalmente feitos de madeira, na qual se esculpem suas cabeças e mãos, e também de tecido. A estrutura dramática do espetáculo pede que o brinquedo seja forte e durável. A opção pela confecção com madeira talvez esteja na preocupação com a durabilidade do objeto, afinal não podem ser bonecos frágeis, já que em uma única função podem tomar cacetadas, sofrer quedas, etc. Os bonecos em tecido normalmente são personagens femininas, que demandam alguma delicadeza. Naturalmente, o boneco poderá ter traços rústicos ou singelos, dependendo do artesão que o construiu. Podem ser de luva, de vara, de fio ou de vara e fio. Suas personagens são pessoas da sociedade (trabalhador, vagabundo, policial, prefeito, bêbado, moça, mulher etc.), figuras fantásticas (deus, capeta, morte) e animais (principalmente o boi e a cobra, muito presentes no folclore brasileiro). É comum encontrarmos os nomes de Benedito ou Simão, como o herói, e Quitéria ou Marieta, como a mocinha, que pode ser também a esposa do coronel.

A relação que o mestre estabelece com seus bonecos sempre ganha destaque em estudos acadêmicos, reportagens e outras pesquisas sobre o Teatro de Mamulengos. Por serem esses mestres homens rústicos, muitas vezes trabalhadores braçais, e quase sempre desprovidos de estudo, a delicadeza e sentimentalismo no trato com os bonecos acabam sendo fatores surpreendentes. Santos cita uma fala colhida do mestre Ginu (1910-1977) que exemplifica a profundidade desta relação:

Esses bonecos são meus amigos das horas tristes. São meus companheiros. Eu não quero ver ninguém dar uma queda neles. Para mim é meu filho. Cada um tem um jeito de vida, cada um uma religião. Adoro meus bonecos. Tenho mais amizade a eles do que a um filho (OLIVEIRA apud SANTOS, 2007, p. 29).

Esse trato de igual para igual, do mestre para o boneco, pode ser o gene da magia que faz com que plateias inteiras acreditem que um boneco tenha vida. Afinal, a crença de seu manipulador na força vital do objeto é primordial para se fazer eficaz a um terceiro, o espectador. Hermilo Borba Filho relata um fato curioso durante suas pesquisas junto aos mestres mamulengueiros (neste trecho ele fala sobre o trabalho do mestre Manuel de Cabedelo):

Todas as figuras de mulher são representadas por bonecas de pano, pois este é o seu sentido de beleza. Confessou-me, como o fez José Petronilo Dutra, o mamulengueiro de Surubim, que pega as bonecas de pano apenas pelas pernas, com "vergonha de colocar a mão por de baixo da saia" (FILHO, 1987, p. 148).

O episódio relatado por Filho nos mostra que a relação íntima entre mestre e boneco é tão verdadeira que até mesmo os valores morais são levados em consideração na interação com o objeto. Essa relação pessoal singular que o manipulador cria com cada boneco permite o domínio completo sobre as características 
do personagem, fazendo com que o jogo de improviso aconteça de forma orgânica, natural, aos olhos do espectador.

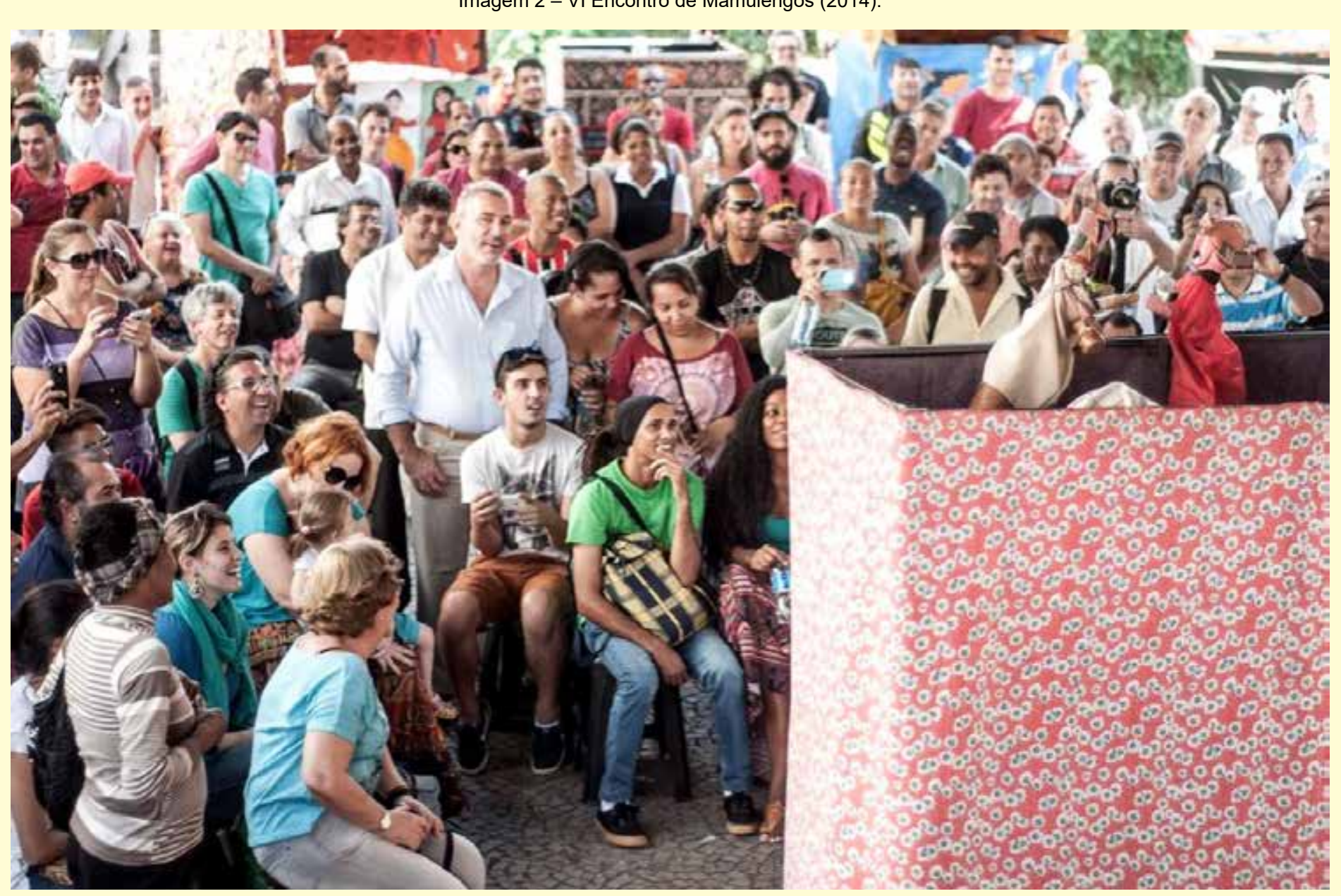

Fonte: Anna Piccolo (acervo pessoal).

A brincadeira de hoje

Apesar das transformações ocorridas ao longo do tempo, o Teatro de Mamulengos resiste e se mantém vivo e atual. Com o advento do rádio, da televisão e, mais recentemente, da internet, as apresentações com mais de cinco horas, por exemplo, perderam sentido. Porém, ao contrário do que se poderia imaginar, Benedito, Quitéria e outros Mamulengos resistiram às chamativas personagens presentes nos programas infantis da TV. O acordeom, a zabumba e o pandeiro continuam divertindo, apesar da música eletrônica, e até a simples montagem da barraca de Mamulengo numa praça pública ainda faz juntar gente.

Podemos conjecturar que justamente essa vida contínua e pulsante, mesmo após a eclosão tecnológica e urbana no Brasil, faça o Mamulengo merecer a alcunha de patrimônio nacional. Para Néstor García Canclini (1994), os processos de urbanização, a indústria cultural, o turismo e outras realidades vividas na atualidade, não devem ser vistos como inimigos do patrimônio e sim como contextos em que os bens históricos se inserem. Tais conjunturas, segundo o autor, devem nos servir ainda para repensarmos o que entendemos por patrimônio e identidade nacional:

Os processos de urbanização, industrialização e massificação da cultura, as migrações e a transnacionalização dos bens materiais e simbólicos, a globalização e as formas de integração econômica exigem a redefinição do que hoje podemos entender por nação. O que concebemos como tal não é unicamente o conjunto de bens e tradições surgidos e mantidos no território historicamente habitado por uma comunidade. A população originária se alimenta, se informa e se entretém com muitos bens e mensagens procedentes do estrangeiro, os quais, porém, vimos incorporando à nossa vida cotidiana (CANCLINI, 1994, p. 95). 
Além dessa resistência nos dias de hoje, o teatro de Mamulengos tem se renovado em termos estéticos com a chegada de novos brincantes, que trazem distintas experiências artísticas anteriores. Conforme Isabela Brochado (2015, p. 80), recentemente houve "um aumento significativo de novos grupos de teatro de bonecos ou bonequeiros solo, que se relacionam com as formas tradicionais de teatro de bonecos do Nordeste". Esses novos grupos apresentam inovações, superações e transformações em relação à linguagem e também às tradições. A orquestra, por exemplo, pode apresentar instrumentos bem distintos dos tradicionais aqui citados, como guitarra e teclado elétricos.

Observamos nos novos trabalhos uma maior utilização dos recursos tecnológicos, como a iluminação e também o sistema de som. Hoje, nas apresentações realizadas em eventos de pequeno a grande porte, é muito comum que a voz do mamulengueiro esteja amplificada por meio de um microfone. Todos parecem concordar que, se temos tecnologia, não há por que o artista sacrificar seu bem-estar físico. Nos temas abordados nas passagens, também há uma relação direta com as características da sociedade contemporânea, como referências ao mundo virtual, por exemplo.

Mesmo os brincantes mais antigos se adaptaram ao mundo globalizado. O teatro de Mamulengos é folclore brasileiro, mas não é uma peça estática de museu - é um fenômeno vivo e diligente, feito por artistas que vivem seu tempo. Danilo Cavalcanti, mamulengueiro e organizador do Encontro de Mamulengos, o maior festival específico sobre a arte, que ocorre em São Paulo anualmente, relata em entrevista:

Até o mestre mais antigo que a gente tem, o mestre Zé de Vina, ele muda (o espetáculo). Ele fala que tem que se adaptar aos dias de hoje, sem perder sua essência [...]. O sítio de hoje tem celular, tem televisão, tem parabólica, tem vinte, trinta canais “ali". Tem o filme que ele quiser ver, se ele quiser, ele compra (CAVALCANTI, 2015, [s.n.]).

Adaptar-se e atualizar-se não são apenas ambição artística e humana, mas também formas de resistir, de não deixar que essa arte desapareça, de comprovar que o Mamulengo não é um fenômeno pertencente ao passado.

Assim, o Tio Sam aparece em forma de boneco na brincadeira de Waldeck de Garanhuns. A cobra gigante que come gente, personagem tradicional do Mamulengo, só atende a comandos em inglês no espetáculo de Chico Simões, referência clara de crítica à dominação norte-americana que atinge diretamente os mestres mamulengueiros. Sabe-se que, como um país capitalista e explorado pelo imperialismo, o Brasil tende à renegação da cultura tradicional de seu povo, em especial das manifestações críticas ao poder. No Mamulengo, as figuras representantes do poder são sempre execradas e ridicularizadas: o policial, o padre, o prefeito, o coronel, etc. O herói, o mais esperto, inteligente e simpático, é sempre uma personagem do povo, muitas vezes um boneco negro.

Certamente, esse tipo de teatro sofreu com a renegação do poder público e, muitas vezes, teve o ostracismo por consequência. Sendo uma tradição passada de pai para filho ou de mestre para discípulo, o teatro de Mamulengos padeceu do desinteresse das novas gerações. Afinal, por muito tempo não se enxergava um futuro digno para os mestres e brincantes. Isabella da Costa Brochado, que participou da elaboração do já citado dossiê de registro do teatro de bonecos brasileiro entregue ao Iphan, descreve a situação social atual dos mestres da seguinte maneira:

\footnotetext{
A grande maioria dos bonequeiros nordestinos, principalmente os mais velhos, vive no interior dos estados, seja nas áreas urbanas ou rurais. A situação econômica atual da maioria é precária, mas poucos podem ser considerados miseráveis. Os mais pobres possuem outras ocupações além do teatro de bonecos, como agricultura de subsistência, pequenos serviços, entre outros. Boa parte mora em casas de alvenaria e possui uma estrutura familiar, não passando necessidades visíveis como fome. Porém, têm pouco acesso aos bens básicos, como saúde e educação, e os que vivem em cidades, em geral, moram em áreas sem saneamento básico (BROCHADO, 2015, p. 80).
}

Ainda segundo a autora, o fato de a maioria dos mestres ter em outras profissões suas formas de 
sustento, e no Mamulengo apenas uma complementação de renda, faz com que eles se afastem do circuito do mercado cultural. Com efeito, diante desta realidade, viajar para se apresentar, por exemplo, torna-se algo complexo no cotidiano dessas pessoas. E, com a ascensão e popularidade dos grandes shows, que trazem como atrativo também grandes equipamentos de luz, som etc., a brincadeira vai perdendo espaço em suas próprias regiões, conforme explica Cavalcanti (2015):

\begin{abstract}
A gente tem os principais (mestres) que viajam mais. Mas, aqueles que a gente desconhece continuam com a mala guardada, continuam com aquela aposentadoria pequena, sem espaço pra brincar. Hoje, na cidade pequena no nordeste, o prefeito quase não contrata os mamulengueiros, contrata uma banda de forró. Ele trabalha com número e Mamulengo não é número [...]. Continua essa tristeza entre eles, pouco trabalho, pouco incentivo, pouco "divulgado".
\end{abstract}

Danilo Cavalcanti é o criador do Encontro de Mamulengos, que está em sua $6^{\mathrm{a}}$ edição este ano e que sustenta o peso da responsabilidade de ser o único grande festival específico na área. Durante o evento, os mestres têm a possibilidade rara de contemplar o trabalho de outros mestres, promovendo a troca de informações, conhecimentos, técnicas e até bonecos, já que muitos deles trazem Mamulengos que confeccionam para vender ou trocar. Este festival se mantém por meio de editais públicos de cultura e com apoios conquistados com um trabalho árduo, que começa um ano antes do evento. Ele preenche parte de uma lacuna que deve provavelmente desaparecer diante das políticas de salvaguarda previstas, sobre as quais discorreremos mais adiante.

Cavalcanti procura reunir os principais mestres atuantes neste festival e fala sobre algumas dificuldades específicas. Relata que muitos mestres, por exemplo, têm medo de voar de avião, outros reclamam da distância, alguns não se sentem à vontade em São Paulo, com o trânsito e outros problemas da metrópole. E ainda observa que aqueles mestres que realizam o Mamulengo tradicional, mais rústico, e que não possuem a característica de adaptação da brincadeira, sofrem mais no contexto da cidade grande, pois, segundo Cavalvanti, muitas vezes o público não interage e o jogo não acontece. Desta forma, podemos concluir que iniciativas relativas a festivais específicos são importantes, mas não dão conta do problema, pois a necessidade maior dos mestres é a valorização em sua própria região.

O Teatro de Mamulengos encontra pouco espaço no mercado cultural, afinal, é um teatro que diz respeito à classe trabalhadora, do campo ou da cidade. Trata-se de uma manifestação que ocorre nas ruas ou outros lugares públicos, para a qual não se cobra ingresso, mas com a qual contribui quem desejar, com quanto puder. Esse teatro fala da vida do povo, das opressões sofridas, das festas populares, sempre de forma muito característica, utilizando verbetes próprios e outras peculiaridades locais. Conforme Santos (2007, p. 20):
O espetáculo do Mamulengo, quer seja urbano ou rural, é destinado a um público espe- cífico. O Mamulengo não satisfaz as necessidades teatrais ou mesmo emocionais do pú- blico intelectual e burguês que habitualmente freqüenta nossos teatros. Quando muito, esse público assiste a uma função por curiosidade, por atitude exótica ou por seu aspec- to folclórico. Fica bastante claro que seu público é o povo, as camadas mais inferiores da sociedade, a gentalha, a rafaméia, o Zé-povinho. A esse povo o mamulengueiro sabe falar, dizendo dos mais diferentes aspectos de suas vidas, transfigurando suas alegrias e dores.

Além disso, equivocadamente, o teatro de bonecos tradicional foi cooptado pelo mercado cultural como um teatro próprio para crianças. Sendo assim, os tradicionais palavrões, pancadarias e personagens politicamente incorretas, como o bêbado, por exemplo, não se enquadram nas pretensões de uma programação direcionada ao público infantil. Esse problema apresenta uma profunda contradição prática, pois o teatro de Mamulengo fica de fora dos eventos teatrais para crianças, mas não encontra espaço na programação adulta, já que é associado ao teatro infantil. Em verdade, este teatro não tem uma faixa etária exclusiva, porque a liberdade na improvisação com os bonecos não permite este tipo de pré-determinação. 
Assim, o espaço restrito para o Mamulengo no mercado cultural fica por conta dos poucos festivais específicos que, como já afirmamos, não dão conta do problema. Por isso, a existência de políticas públicas culturais para garantir a atividade de mestres e companhias teatrais que se dedicam ao Mamulengo se faz necessária e urgente. Conforme Izabela Brochado (2015, p. 81):

\begin{abstract}
Embora haja um reconhecimento da importância dos bens culturais populares através das Leis de Patrimônio efetuadas pelos governos estaduais e municipais que têm como objetivo reconhecer a importância de Mestres e Grupos da Cultura Popular, no entanto, elas são bastante restritas, considerando-se a baixa quantidade de mestres agraciados em relação ao quantitativo geral, o que explica a falta de políticas públicas consistentes e permanentes; e a frágil, para não dizer quase omissa, relação do poder público, nas suas várias instâncias, com esses "tipos" de teatro - ou de manifestação cultural de caráter popular.
\end{abstract}

Neste contexto, o reconhecimento do teatro de bonecos tradicional como Patrimônio Imaterial Cultural do Brasil pelo Iphan foi recebido com ares de vitória pelas pessoas que acompanham a luta dos mestres mamulengueiros. Na prática e de início, o título oferecerá a cem mestres um prêmio de reconhecimento no valor único de 30 mil reais. Porém, a expectativa é que este reconhecimento viabilize, entre outras coisas, a criação de políticas públicas específicas que garantam a preservação e a difusão desta arte. Mas Danilo Cavalcanti (2015) lembra que esta é só a primeira conquista de uma luta que segue: “Talvez esse reconhecimento comece abrir portas na educação. Lutar pela salvaguarda, pela aposentadoria dos mestres. Mas, é tudo muito difícil. Tá começando. Talvez daqui uns dez ou quinze anos eles estejam numa vida melhor, quem estiver vivo ainda".

O título de patrimônio pode ser uma alavanca para que as prefeituras e a populações locais onde vivem os mestres passem a valorizá-los. É fundamental entendermos que a continuidade do trabalho destes mestres e a preservação de seus bens culturais não traz benefícios apenas para o próprio mestre individualmente, mas para toda sociedade.

No dossiê elaborado para registro desse patrimônio (BRASIL, 2014) consta uma série de propostas de ações de salvaguarda, colhidas em pesquisa de campo com mestres do Teatro de Mamulengo. Em relação às ações destinadas aos mestres, reivindicam-se, entre outras coisas, um plano de aposentadoria. Para a circulação e produção das brincadeiras, propõe-se, por exemplo, o estabelecimento de cotas mínimas para a contratação das apresentações em eventos, além de políticas públicas de fomento. São citadas também propostas para a preservação dos elementos materiais da brincadeira e do acervo da história do teatro de bonecos popular. As questões que envolvem a transmissão de saberes têm especial atenção no relatório, que elenca propostas para a criação de prêmios e a difusão desta manifestação no âmbito escolar, do ensino básico ao superior, entre outras coisas. Reivindica-se, ainda, a participação dos brincantes em editais e licitações públicas e a prioridade para os mestres mais velhos.

Muitas destas ações deverão ter participação efetiva das prefeituras. Aqui, ficam evidentes os benefícios sociais para os municípios, como o status turístico conferido a uma cidade por possuir um mestre do teatro de bonecos tradicional do Brasil, reconhecido oficialmente como patrimônio cultural. Para tanto, é preciso garantir vida digna aos mestres antigos, incentivar a formação de novos brincantes por meio de cursos, oferecer condições de produção em espaços públicos e preservar os bens já existentes, ou seja, os espetáculos e objetos (barraca, bonecos, adereços etc.), entre outras medidas que podem ser tomadas pelo poder público, acrescidas, obviamente, da garantia da assiduidade das apresentações para apreciação do público local e turistas.

É possível conjecturar, sob o título de patrimônio, que este teatro, bem como seus artistas, cheguem mais facilmente ao seu público e que seja possível garantir a produção contínua de espetáculos. E até mesmo permite vislumbrarmos que as novas gerações conheçam e se interessem por esta arte. 


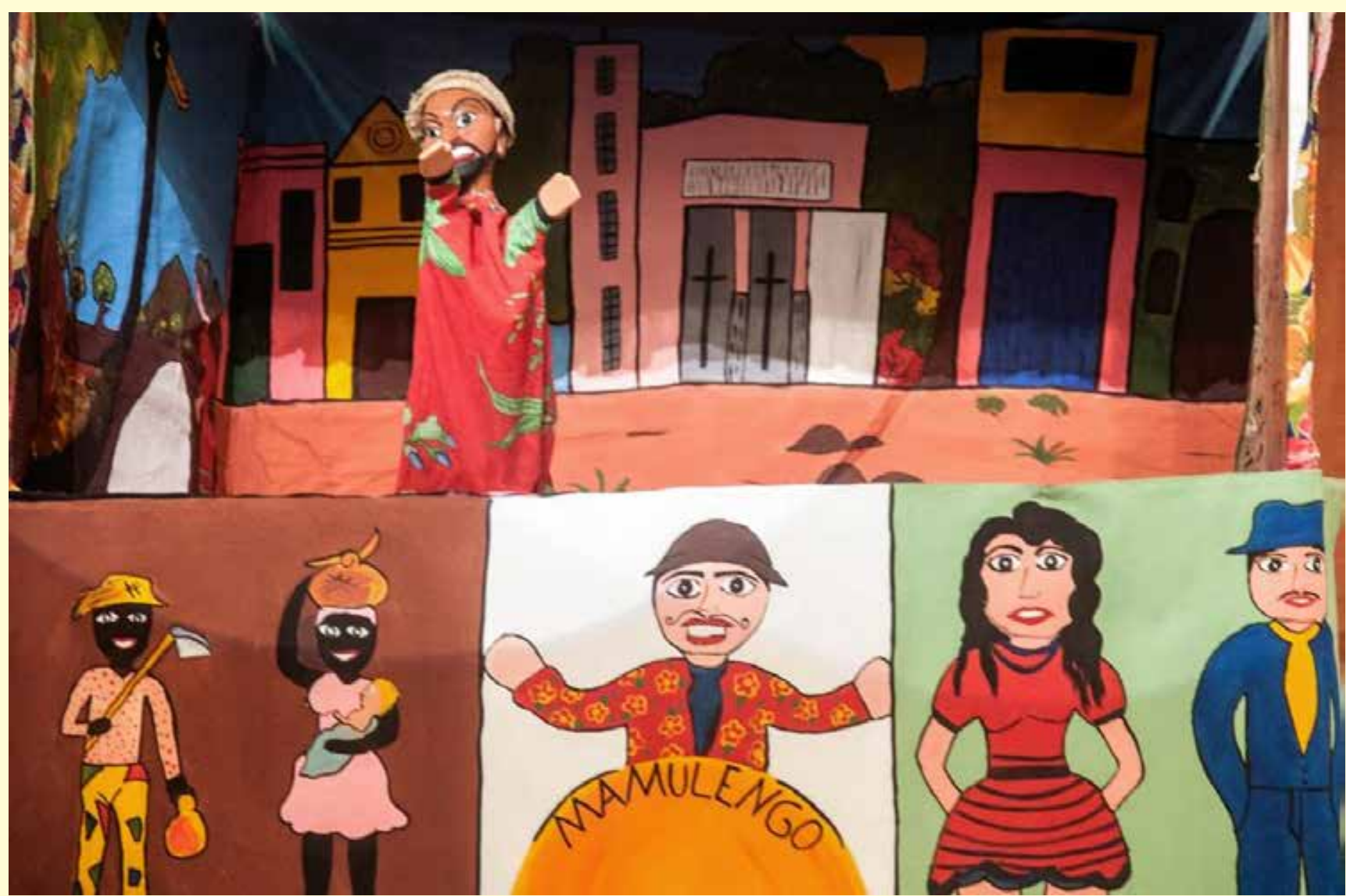

Fonte: Anna Piccolo (acervo pessoal).

\title{
Uma brincadeira reconhecidamente brasileira
}

Abordamos os possíveis ganhos práticos, imediatos e em longo prazo, do título de patrimônio imaterial para o Teatro de Mamulengos, cujos aspectos simbólicos são de demasiada importância, e cujo campo de debate é tão profícuo que seria impossível um aprofundamento neste artigo. No entanto, é necessário que discorramos, ainda que brevemente, sobre algumas questões do tema a fim de caminharmos para um posfácio justo à reflexão que propusemos aqui.

O termo "patrimônio" está diretamente ligado à ideia de propriedade. E, se aquilo que pertence a alguém é de sua propriedade, portanto, há também a vinculação à noção de pertencimento. Conforme o antropólogo José Reginaldo Santos Gonçalves (2007, p. 122):

\begin{abstract}
Assim como a identidade de um indivíduo ou de uma família pode ser definida pela posse de objetos que foram "herdados" e que "permanecem" na família por várias gerações; também a identidade de uma nação pode ser definida pelos seus monumentos - aquele conjunto de bens culturais associados ao passado nacional. Estes constituem um tipo especial de "propriedade": a eles se atribui a capacidade de evocar o passado e, desse modo, estabelecer uma ligação entre passado, presente e futuro. Em outras palavras, eles garantem a "continuidade" da nação no tempo.
\end{abstract}

A apreciação de um espetáculo de Mamulengo é um verdadeiro mergulho na cultura brasileira. É inequívoco afirmar que o teatro de Mamulengos é tipicamente brasileiro, em todos os termos possíveis: linguagem oral, estética, modo de fazer, modo de se autogerir, de ser transmitido etc. Obviamente, estamos tratando deste assunto de forma abreviada, já que seria justo um aprofundamento em cada aspecto.

Outro destes aspectos identitários brasileiros do teatro de Mamulengo é o espectador. Neste teatro, aquele que assiste não se encontra sentado confortavelmente na posição de apreciador somente, ele é um 
elemento ativo e vital para o espetáculo. Tratamos de um tipo de apresentação que exige uma atuação direta do público e que não acontece quando encontra um espectador passivo.

O Mamulengo trabalha sobre as características do seu povo, seus costumes, problemas sociais, modos de viver e idiossincrasias. Desta forma, o indivíduo que não esteja inserido, ou não conheça a cultura onde se encontra o Mamulengo, terá uma provável dificuldade de interação. Danilo Cavalcanti (2015) conta que, durante uma apresentação em Portugal, viveu uma experiência frustrante, já que o público não correspondia às brincadeiras e convites à participação. Também narra que já passou por dificuldades semelhantes na região sul do Brasil, por ter tido o infortúnio de se deparar com um público conservador, que por vezes proferia expressões racistas assim que um boneco de cor negra entrava em cena.

O Mamulengo é uma expressão viva da cultura brasileira e fala ao brasileiro, remetendo sempre a aspectos de sua identidade. Desta forma, é compreensivo que um europeu não consiga interagir com a brincadeira, apesar de ser capaz de admirá-la. Remetendo-nos novamente ao significado do termo patrimônio, podemos imaginar essa relação como a de uma pessoa que entra na casa de um estranho. Ela pode admirar a beleza dos móveis, a disposição dos objetos, a combinação de cores etc. No entanto, cada coisa ali para ela não será mais que um objeto, enquanto que, para o morador, terá significados para além do material.

Nesse sentido, um indivíduo que não aceite as raízes africanas da nossa cultura certamente se sentirá afrontado com o conteúdo desta manifestação popular. Afinal, como já dito, a cultura afrodescendente está presente no Mamulengo de forma intrínseca, tendo, entre outras coisas, uma personagem negra como herói.

Quanto ao uso das denominações, os termos "imaterial" ou "intangível” foram adotados para designar determinadas categorias de patrimônios que não se limitam a objetos, prédios ou monumentos. Porém, Gonçalves (2007, p. 218) nos chama a atenção para o fato de que não há patrimônio sem materialidade, embora a noção de imaterialidade expresse "a moderna concepção antropológica de cultura, na qual a ênfase está nas relações sociais, ou nas relações simbólicas, mas não especificamente nos objetos materiais e nas técnicas". Ainda segundo o autor, é importante o entendimento de que se trata de uma categoria ambígua, que transita entre o material e o imaterial. É particularmente interessante pensar nesta questão nos referindo ao teatro de Mamulengos. Afinal, a essência deste fenômeno está justamente no jogo entre o material e o imaterial, o objetal e o humano, o ser e o não-ser, parafraseando Felisberto Sabino da Costa (2001).

Um boneco Mamulengo, exposto num museu, revela seu vazio. A abertura no tecido para se colocar a mão do manipulador pressupõe a presença humana, que logo propõe uma atuação artística, um evento, um fenômeno. Por outro lado, se podemos dizer que o boneco não é nada sem o manipulador, também é evidente que o teatro de Mamulengos é impossível sem a existência do objeto boneco. Ou seja, o fenômeno deste teatro está justamente na mediação entre o imaterial e o material, bem como entre o passado e o presente.

Não podemos dissociar o Mamulengo de um fenômeno teatral, multimídia, em que a participação do espectador é imprescindível. E que, portanto, pressupõe a experiência. Desta forma, a difusão desta arte e, consequentemente, o acesso do público a ela, é um direito do povo brasileiro, já que a ele pertence o Teatro de Mamulengos. Está aí o maior sentido de conquista que adquiriu o reconhecimento do Iphan: que o Brasil todo se aproprie do Mamulengo, como ele há muito tempo e tão bem se apropriou do povo brasileiro.

\section{Referências}

BENJAMIN, Walter. A obra de arte na era de sua reprodutibilidade técnica. 1955. Disponível em: < http://ideafixa.com/ wp-content/uploads/2008/10/texto_wbenjamim_a_arte_na_era_da_reprodutibilidade_tecnica.pdf $>$. Acesso em: 08 jul. 2015.

Obras escolbidas. Magia e técnica, arte e política. Ensaios sobre literatura e história da cultura. São Paulo: Brasiliense, 1987, v. 1.

BORBA FILHO, Hermilo. Fisionomia e Espirito do Mamulengo. Rio de Janeiro: INACEN, 1987.

BRASIL. Ministério da Cultura. Dossiê Interpretativo Registro do Teatro de Bonecos Tradicional do Nordeste: Mamulengo, Casimiro Coco, Babau e João Redondo. Brasília: Iphan, 2014. 
Dossiê

BROCHADO, Isabela. A participação do público no Mamulengo. Móin-Móin - Revista de Estudos sobre Teatro de Formas Animadas, Jaraguá do Sul, v. 3, n. 3, p. 36-37, 2007.

. O mamulengo e as tradições africanas do teatro de bonecos. Móin-Móin - Revista de Estudos sobre Teatro de Formas Animadas, Jaraguá do Sul, v. 2, n. 2, p. 140-155, 2006.

. Teatro de bonecos popular do nordeste - Mamulengo, babau, Casimiro Coco: Patrimônio Cultural do Brasil. Arte da cena, Goiânia, v.1, n.2, p. 67-87, 2015. Disponível em: < http://www.revistas.ufg.br/index.php/artce/index $>$. Acesso em: 12 jul. 2015.

CANCLINI, Néstor García. O patrimônio cultural e a construção imaginária do nacional. Revista do Iphan, v. 3, n. 23, p. $94-$ 115, 1994.

CAVALCANTI, Danilo. Entrevista, mar. 2015. Entrevistadora: Kely Elias de Castro. Itanhaém, SP. Arquivo digital. Entrevista concedida exclusivamente para este artigo (não transcrita, não publicada).

COSTA, Felisberto Sabino da. A Poética do Ser ou Não Ser: procedimentos dramatúrgicos no Teatro de Animação. 2001. Tese (Doutorado em Artes) - Universidade de São Paulo, São Paulo. 2001.

GONÇALVES, José Reginaldo Santos. Antropologia dos objetos: coleções, museus e patrimônios. Rio de Janeiro: Editora Garamond, 2007. (Coleção Museu, Memória e Cidadania).

SANTOS, Fernando Augusto Gonçalves. Mamulengo: o teatro de bonecos popular no Brasil. Móin-Móin - Revista de Estudos sobre Teatro de Formas Animadas, Jaraguá do Sul, v. 3, n. 3, p. 16-35, 2006.

SIMÕES, Chico. Mamulengueiro é ator? Móm-Móin - Revista de Estudos sobre Teatro de Formas Animadas, Jaraguá do Sul, v. 1, n. 1, p. 119-145, 2005. 